Richard O. Binswanger

Anders als bei Bundespräsident Hans-Rudolf Merz geht die Rolle des Chefarztes über die eines Primus inter pares hinaus.

\footnotetext{
* Aus stilistischen Gründen wird die männliche Form verwendet. Frauen sind ausdrücklich mitgemeint.
}

Dr. med. Richard O. Binswanger Radiologie und Nuklearmedizin FMH

Führungsschule Bodensee

Münsterlingen

Oberer Seeweg 9

CH-8597 Landschlacht

r.binswanger@bluewin.ch

\section{Kein Primus inter pares}

Anlässlich eines unserer Kurse bezeichnete ein Chefarzt seine Stellung als die des Primus inter pares, was sofort Widerspruch auslöste. Warum? Jeder Arzt* im Spital ist seiner Institution durch seine Profession verpflichtet, also hauptsächlich durch Dienstleistung an Patienten in seinem Fachgebiet. Die Verpflichtung des Chefarztes geht weiter. Er führt seine Klinik und hat

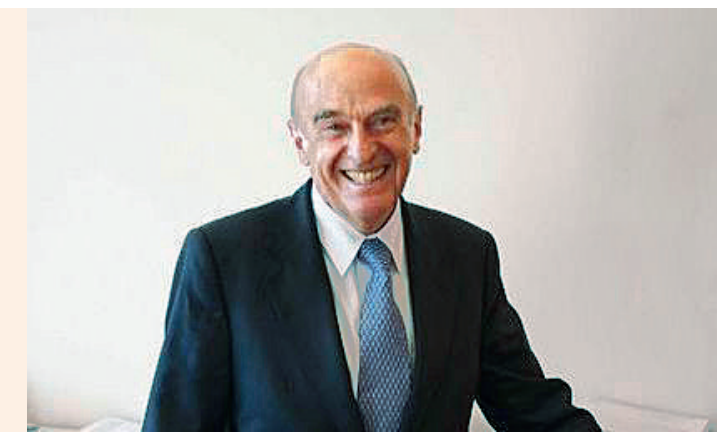

damit eine zweite Aufgabe. Er ist also nicht gleich. Dieser Unterschied ergibt sich nicht aus der Rangordnung, sondern aus der Tätigkeit. Es geht dabei um die Sache und nicht um die Person. Der Unterschied muss vom Chefarzt und von seinen (ärztlichen und nichtärztlichen) Mitarbeitern wahrgenommen und wahrgemacht werden. Führung hebt den Klinikleiter heraus und verpflichtet ihn, und zwar stärker als die anderen.

\section{Führen heisst Dienst am Ganzen}

Die Aufgabe steht im Zentrum. Sie ist für jede Klinik zu definieren, und zwar am besten unter Einbezug der Mitarbeitenden. Ihren Inhalt müssen alle kennen und es muss immer wieder darüber gesprochen werden. Aus der Aufgabe leitet sich die Struktur ab. Aufgabenverständnis und Struktur prägen die Kultur einer Institution. Die Kultur prägen ist der stärkste Hebel der Führung. Nur was zum kulturellen Reflex geworden ist, ist gewonnen, wenn auch nicht für immer. Arbeit am Aufgabenverständnis, an der Struktur und der Kultur ist dauerhaft notwendig. Der Chefarzt muss dazu immer wieder den Anstoss geben. Er hat dabei nicht nur seine Klinik im Auge zu behalten, sondern deren Beitrag zum Ganzen, also dem Spital und dessen Umfeld. Dies ist eine notwendige Dienstleistung, auch eine an den Mitarbeitern.

\section{Die Pflicht zum Führen}

Der Chefarzt darf nicht, er muss führen. Kommt er dieser Pflicht nicht nach, entstehen Unsicherheit und Zwist. Diese absorbieren ernorme Kräfte, die dann dort fehlen, wo sie notwendig sind. Es etablieren sich informelle Führungsmechanismen und -strukturen. Jeder erfahrene Arzt hat solches in seiner Karriere erlebt und bittere Erfahrungen gemacht. Unter Führungsschwäche leiden alle. Am meisten aber leidet der Chefarzt selbst, er hat sich in eine Abhängigkeit gebracht, Abhängigkeit von Mechanismen und Personen, die er selbst nicht mehr steuern kann.

\section{Der Lohn guter Führung}

Gute Führung führt jede Klinik zum Erfolg. Damit ist medizinischer und wirtschaftlicher Erfolg gemeint. Das Ansehen der Klinik wächst innerhalb und ausserhalb des Spitals. Dies allein ist schon Anlass zur Freude. Damit aber nicht genug. Gute Führung spart Zeit, motiviert und bindet Mitarbeiter. Konflikte werden ausgetragen und motten nicht unter einer Decke. $\mathrm{Ob}$ eine Klinik gut geführt ist, merken Patienten und Angehörige schon beim ersten Kontakt. Die Stimmung ist besser, die Mitarbeiter sind «aufgestellt». Es herrschen gegenseitige Achtung und Respekt. Dies alles merkt auch der Klinikchef, er wird geachtet und fühlt sich getragen von seinem Umfeld. Er erhält Freiraum, um sich anderem, insbesondere seiner Kernaufgabe, dem Arztsein, zuzuwenden. Ein grosser Lohn! 